\title{
Self-Help Research and the Public Mental Health System
}

\author{
Thomas J. Powell ${ }^{\prime}$ and Marcia J. Cameron \\ Center for Self-Help Research and Knowledge Dissemination, University of Michigan, \\ Ann Arbor
}

Discusses views of self-help leaders, researchers, and policy makers from the public mental health system about collaborative research with self-help groups. Topics include assumptions underlying collaborative research, barriers to collaborative research, and the potential benefits of collaborative research. Special attention is given to the rationale and methods for including minorities in self-help research. Initial discussions were held at a meeting convened by the NIMH-funded Center for Self-Help Research and Knowledge Dissemination at the University of Michigan.

A Center for Self-Help Research and Knowledge Dissemination has been established at the University of Michigan funded by a 5-year NIMH grant. It is one of two such currently funded centers; the other one is at the University of California, Berkeley (Steven P. Segal, Principal Investigator).

The mission of the Michigan Center is to create an environment in which self-help leaders, multidisciplinary researchers, and policy makers from the public mental health system can collaborate on research and knowledge dissemination projects. These projects will be with self-help programs especially relevant to persons with serious mental illness. Specific goals include generating knowledge about (a) how self-help and professional service providers can coordinate their services for people with serious

${ }^{1}$ All correspondence should be sent to Thomas J. Powell, Center for Self-Help Research and Knowledge, The University of Michigan, 505 East Huron St., Ann Arbor, Michigan 48104-1567. 
mental illness, (b) how self-help groups can improve the effectiveness of their programs, (c) how persons with serious mental illness can gain access to potentially less stigmatizing, non-mental health specialized self-help groups such as Alcoholics Anonymous (AA), and (d) how the public mental health system can be more supportive in organizational terms of self-help based, consumer-run programs. The initial studies related to these goals involve collaboration with members of the Manic-Depressive and Depressive Association, Schizophrenics Anonymous, dual recovery AA groups, and consumer-run drop-in centers. The results of these studies will be disseminated to self-help groups, to the public mental health system, to self-help clearinghouses and centers, and to higher education programs in the health and human services. All of the Center's activities will be carried out with an explicit focus on the concerns and perspectives of minority persons (Powell, Yeaton, \& Janssen, 1990).

To support this mission, the Center formed a National Advisory Council made up of seven self-help leaders, four researchers, and three public mental health officials. Eight of these members (three self-help, three research, and two public mental health) participated in the first meeting of the Council held in October 1990. This paper grew out of the discussions at that meeting of basic assumptions, barriers, and benefits related to collaborative research. The Council felt that meaningful research with self-help programs requires the involvement of self-help leaders in the formulation of the questions, the design of the research, and the dissemination of the results. It also felt that the research must be geared to preserving and enhancing the autonomy and authenticity of self-help programs while aligning itself with the goals, if not the practices, of the public system (Powell, 1990).

It was assumed that experiential knowledge - based on "living through and resolving a problem" rather than professional knowledge based on nonparticipant observation and scientific study (Borkman, 1990a) - is an essential ingredient of self-help programs. It often is the most important element of the self-help culture. Thus researchers should be challenged to incorporate experiential language and concepts in their theoretical frameworks, measurement operations, research reports, and dissemination activities.

The constantly evolving nature of self-help programs should also receive more attention from researchers. Programs change as members evolve from novices to veterans and as new cohorts of members replace old ones. Often substantial changes occur as fledgling, informally structured groups become well-developed, formal groups, or as developed groups decline (Weber, 1982). The magnitude and direction of these changes should be assessed, ideally by longitudinal methods (Quinn \& Cameron, 1983). A 
single cross-sectional view may be no more representative of the program than snapshots of babies are of adults. To better represent these programs, researchers should track organizational changes in such areas as leadership structure, external relations, and the level of formality associated with organizational processes (e.g., the use of printed materials).

Heterogeneity should be considered the norm in self-help groups; it results from variations in organizational structure and from the distinctive program content required by people in different situations with different problems. For example, Compassionate Friends, a group for parents who have experienced the death of a child, has created a distinctive program that is from that of a 12-step group such as Alcoholics Anonymous, or a group for people with illness such as AIDS or rheumatoid arthritis. Resisting their "lumper" tendencies, researchers need to describe these differences and observe their relationship to other variables (Levy, 1984). And even within a single organization such as $\mathrm{AA}$, researchers might ponder the difficulty of drawing a probability sample representative of its heterogeneity (E. Kurtz, 1988).

\section{BARRIERS TO COLLABORATIVE RESEARCH}

Much of the discussion centered on barriers emanating from the conflicting views of self-helpers, researchers, and public officials about what are the most important research questions and the most appropriate research methods. These barriers grow larger with the addition of the negative personal experiences many self-helpers have had with professional services (Chamberlin \& Rogers, 1990; Zinman, Harp, \& Budd, 1987). For their part, professionals sometimes react as if their livelihood was threatened by self-help services. With more reason, but not with more justification, professionals react to self-help as a threat to their hegemony in the services field (Chesler, 1990). Each of these potential barriers needs to be better understood.

Policy-making public mental health officials as well as researchers traditionally prefer quantitative methods. In contrast, self-help leaders are more comfortable with qualitative methods because they regard them as better suited to the complexity of the self-help processes. They feel that qualitative research methods require the researcher to develop an "ear" for experiential phenomena and there is less danger that the researchers will impose their own structures on them. Qualitative methods also lend themselves better to describing changes over time, and to dealing with exceptions and subtly nuanced differences both within and across various groups. Yet one must also understand why public officials and others may have difficulty using findings 
based on qualitative data. One answer is to use rigorously designed and implemented research procedures and to assess their reliability and validity (Cook \& Reichardt, 1979; Denzin, 1987; Glaser \& Strauss, 1967; Rappaport et al., 1985). At minimum, there should be detailed field notes that predate and are separable from the research report.

Council members felt that research sponsors should be urged to fund more descriptive, qualitative research. One of the strongest recommendations of the Council was not to rush into premature quantitative studies before acquiring an understanding of the basic phenomenology of the group. Even more caution should be exercised before moving into experimental evaluations (Campbell, 1987; Canner, Forman, Prudhomme, Berge, \& Stamler, 1980). Left to themselves, the Council noted, policy makers and researchers favor effectiveness studies, which inevitably question the justification of self-help groups. Self-helpers, on the other hand, point to their large memberships as justification of their existence. Participation by its very nature, they point out, is responsive to members' needs for information, relationship, and concrete assistance. Naturally, they will not willingly become vulnerable to researchers who do not understand the nature of self-help or the ways in which its benefits are likely to become manifest. Given these circumstances, only sensitive and supportive researchers will be successful in securing cooperation for studies that go beyond assessing popularity and recording members' stories. Their success is also likely to be proportional to their acceptance of self-help arguments about the need to focus research on how to attract more members and to improve their participation and satisfaction with the organization. A positive response to these arguments will be convincing evidence that researchers can allow selfhelp leaders to contribute to the substance of the research agenda and not just to the shape of specific research questions.

As a whole, the Council recommended that the Center invest more in participation questions and less in the long-term effectiveness of this participation. This would be consistent with an appreciation for the unavoidable threats to validity inherent in the complexity of the phenomena and the limitations on obtaining experimental control.

Specifically, the council recommended the Center assign higher priority to the participation questions already built into its study of the Detroit affiliate of the National Depressive and Manic-Depressive Association. Elaborations of the design will focus more attention on how the components of the intervention with mood disorder patients at a university and public mental health facility are related to subsequent participation in the self-help group. For example, data will be collected to analyze how the staff and the referent-empowered self-help sponsors influence the participation process in a differential manner. Particular attention will be 
given to how African-Americans experience the intervention. The focus on long-term effectiveness will be maintained via the multiple interrupted time series design, but henceforward it will be broadened to include these other questions (Cook \& Campbell, 1979).

Even when self-help leaders have influenced the design by helping select and create research instruments, they may be justifiably concerned about involving their groups in studies because of their vulnerability to outside influences. Despite good intentions, and merely by their presence, researchers can interfere with the self-help process (Chamberlin \& Rogers, 1990). Groups, which are proud of their spontaneity, fear they will be inhibited by the presence of outside observers and impersonal research instruments. Countering these concerns, other Council members felt self-help groups and their members were very adaptable and resilient. In any event, it must be remembered that there is an ongoing independent process of groups forming and dying for reasons quite apart from their having participated in research (Maton, Leventhal, Madara, \& Julien, 1989).

A barrier specific to mental health consumer/expatient/survivor groups stems from the feeling that professionals abridge basic client rights and are insensitive to the toxic and debilitating side effects of drugs. Researchers must acquire a consciousness about consumer experiences and concerns before collaboration can proceed. On the professional side, the additional work required of staff will be a barrier unless they see some possibility that the research will enrich the service program and lighten their burden.

What emerged from the Council's discussions was a greater appreciation for the tenuous nature of the relationships between self-help groups and researchers, and public officials. To strengthen these ties, various constituent groups need to be more supportive of each others' needs and interests. Yet they must refrain from eroding the integrity of these varying groups and their different perspectives. Collaboration - rather than integration - is the state sought among these constituencies. Integration, if it involves giving up some integrity and autonomy, is then exactly the opposite of what is sought. For collaborative research should have as its metagoal a strengthening the integrity and autonomy of self-help groups, even though its more immediate focus is on accessibility and effectiveness issues.

\section{BENEFITS OF COLLABORATIVE RESEARCH}

Simply being chosen as research partners, affirms self-help groups. By recognizing the part self-help groups play and can play in a 
comprehensive system of care, effectiveness of that system is enhanced. In making decisions about numerous research design issues, self-help groups are stimulated to clarify and elaborate their priorities. The stimulus also serves to strengthen decision-making structures by promoting their exercise. By becoming active participants in the research, self-help groups will be empowered by their increased capacity to recruit, retain, and meaningfully involve members in their programs (Rappaport et al.; 1985).

A major concern of organized self-help groups is to become a more effective resource for African-Americans and other minority cultural groups (Gutierrez, Ortega, \& Suarez, 1990). Although AfricanAmericans, for example, have a rich tradition of informal support networks, they have not had adequate access to specialized information about specific conditions such as bipolar disorder nor to role models who have successfully dealt with the double dose of discrimination associated with minority and expatient status (Caldwell, 1983; Neighbors, Elliott, \& Gant, 1990).

One way for research to respond to this situation is to study ways that specialized self-help groups, such as those organized around recurrent depressive and bipolar disorders, develop and maintain contacts with the informal self-help networks that already exist in culturally distinct communities (Hamilton, 1990). The Center's MDDA study takes this approach. This also seems to be the approach of the National Alliance for the Mentally Ill's Minority/Ethnic Concerns Network. A separate approach would be to study the development of viable minority-controlled groups, such as the SOSAD (Save Our Sons and Daughters) organization in Detroit.

In between are studies of special groups that have been created by minorities in majority self-help organizations. AA, for example, has long had special groups for physicians and clergy. More recently, increased attention has been paid to its special groups for ethnic and other discriminated-against minorities such as gay men and lesbians and people who are mentally ill (Alcoholics Anonymous, 1984, 1989, 1990). The Center is conducting a study of people who had contact with AA groups oriented to people with mental illness. The focus of this study is on the factors related to continuance or discontinuance in these groups. Part of the appeal of this study is that a significant proportion of the people having contact with these AA groups are African-American.

Collaborative research can also be a means by which professionals develop new resources. As they become more knowledgeable, research suggests they will refer more clients to self-help groups (L. F. Kurtz, Mann, \& Chambon, 1987). The tendency of self-help research to be a force humanizing the professional system is another benefit (Borkman, 1990b). As 
self-help organizations compensate for the deficiencies of the professional system and mount advocacy campaigns, they serve to humanize the system. This also happens as trainees in preprofessional educational programs are exposed to self-help knowledge. This in turn depends on the availability of empirical studies which are the basic units of professional curriculums. In the absence of such research, students obtain their degrees without learning how to use self-help resources and stimulate their development.

\section{DIRECTIONS FOR FUTURE RESEARCH}

A major theme of the National Advisory Council centered on the importance of answering questions about participation in self-help groups. What factors - especially among the potentially manipulable social kind - are related to joining self-help groups? For those who decide to opt out (i.e., decide not to join a self-help group or drop out of one), what social factors are related to this decision?

Regarding pathways to self-help groups, researchers were particularly interested in how people who come of their own initiative differ from those who attend at the recommendation of professionals, and how both of these categories differ from those who are pressured by courts or treatment centers. How are these pathway differences related to continuation and the potential for long-term benefits? A related question, and one that is particularly salient for the Center's projects, asks how the presence of self-help sponsors in public system settings (hospitals and community mental health centers) affects participation?

Instead of, or to balance long-term summative evaluations, researchers felt there should be more attention to formative and process questions (Maton, 1988). To what extent is the group cohesive? To what extent does group activity focus on issues relevant to the group? Are members increasing their coping skills? What interactions seem most involving and most beneficial to members?

Policy makers were interested in how involvement in self-help organizations could become part of an individual's community support system. How can self-help groups be empowered to take their place alongside more familiar community institutions (church, school, welfare department, health clinic, job site, etc.) as primary community supports?

A great deal of interest among all three constituencies centered on the impact of the research operation on self-help groups. Explicating some of the questions alluded to earlier: How do observation and interviewing affect group functioning? How do joint self-help/professional interventions affect the self-help organizations? How does research stimulate change in 
leadership roles and is the change for the better or not? How does the linkage with public mental health system facilities (i.e., group homes, community mental health centers, and mental hospitals) alter the anonymity and confidentiality provisions of most community-based self-help groups, and what are the consequences of this change? An overriding interest was evident in research that would focus on how to maintain and enhance the autonomy and authenticity of self-help organizations in this changing climate of self-help/professional relations.

Ongoing forums should be developed in which representatives of the three constituencies could discuss their research-related concerns, interests and priorities. By providing one such forum and by incorporating its insights into its own research program, the Center is striving to contribute to the long-term vitality and effectiveness of self-help programs.

\section{REFERENCES}

Alcoholics Anonymous. (1984). The AA member-Medications and other drugs. New York: A.A. World Services Office.

Alcoholics Anonymous. (1989). A.A. and the gay/lesbian alcoholic. New York: A.A. World Services Office.

Alcoholics Anonymous. (1990). The A.A. group. New York: A.A. World Services Office.

Borkman, T. (1990a). Experiential, professional and lay frames of reference. In T. Powell (Ed.), Working with self-help. Silver Spring, MD: National Association of Social Workers.

Borkman, T. (1990b). Self-help groups at the turning point: Emerging egalitarian alliances with the formal health care system? American Joumal of Community Psychology, 18, 321-332.

Caldwell, F. J. (1983). Alcoholics Anonymous as a viable treatment resource for black alcoholics. In T. S. Watts \& R. Wright, Jr. (Eds.), Black alcoholism: Toward a comprehensive understanding (pp. 85-99). Springfield, IL: Charles C Thomas.

Campbell, D. T. (1987). Guidelines for monitoring the scientific competence of preventive intervention research centers. Knowledge: Creation Diffusion, Utilization 8(3), 389-430.

Canner, P. L., Forman, S. A., Prudhomme, G. J., Berge, K. G., \& Stamler, J. (The Coronary Drug Project Research Group). (1980). In(luence of adherence to treatment and response of cholesterol on mortality in the coronary drug project. New England Journal of Medicine 303, 1037-1041.

Chamberlin, J., \& Rogers, J. A. (1990). Planning a community-based mental health system: Perspective of service recipients. American Psychologist, 45, 1241-1244.

Chesler, M. A. (1990). The "dangers" of self-help groups: Understanding and challenging professionals' views. In T. J. Powell (Ed.), Working with self-help (pp. 301-324). Silver Spring, MD: National Association of Social Workers.

Cook, T. D., \& Reichardt, C. S. (1979). Qualitative and quantitative methods in evaluation research. Beverly Hills: Sage.

Cook, T. D., \& Campbell, D. T. (1979). Quasi-experimentation. Chicago: Rand McNally.

Denzin, N. K. (1987). The recovering alcoholic. Beverly Hills: Sage.

Glaser, B., \& Sirauss, A. (1967). Discovery of grounded theory: Strategies for qualitative research. Chicago: Aldine.

Gutierrez, L., Ortega, R. M., \& Suarez, S. (1990). Self-help and the Latino community. In T. J. Powell (Ed.), Working with self-help (pp. 218-236). Silver Spring, MD: National Association of Social Workers. 
Hamilton, A. (1990). Self-help and mutual aid in ethnic minority communities. In A. H. Katz \& E. 1. Bender, Helping one another: Self-help groups in a changing world (pp. 47-61). Oakland, CA: Third Party.

Kurtz, E. (1988). A.A.: The story. Cambridge: Harper/Hazclden.

Kurtz, L. F., Mann, K. B., \& Chambon, A. (1987). Linking between social workers and mental health mutual-aid groups. Social Work in Health Care, 13(1), 69-78.

Levy, L. H. (1984). Issues in research and evaluation. In A. Gartner \& F. Riessman (Eds.), The self-help revolution (pp. 105-172). New York: Human Sciences.

Maton, K. I. (1988). Social support, organizational characteristics, psychological well-being, and group appraisal in three self-help group populations. American Joumal of Community Psychology, 16, 53-77.

Maton, K. I., Leventhal, G. S., Madara, E. J., \& Julien, M. (1989). Factors affecting the birth and death of mutual-help groups: The role of national affiliation, professional involvement, and member focal problem. American Joumal of Community Psychology, 17, $643-671$.

Neighbors, H. W., Elliott, K. A., \& Gant, L. M. (1990). Sell-help and black Americans: A strategy for empowerment. In T. J. Powell (Ed.), Working with self-help (pp. 189-217). Silver Spring, MD: National Association of Social Workers.

Powell, T. J. (1987). Self-help organizations and professional practice. Silver Spring, MD: National Association of Social Workers.

Powell, T. J. (1990). Working with self-help. Silver Spring, MD: National Association of Social Workers.

Powell, T. J., Yeaton, W. H., \& Janssen. (1990). The agenda for the University of Michigan Center for Self-Help Research and Knowledge Dissemination. Paper Presented at the Annual Convention of the American Psychological Association, Boston, MA.

Quinn, R. E., \& Cameron, K. (1983). Organizational life cycles and shifting criteria of effectiveness: Some preliminary evidence. Management Science, 29, 33-51.

Rappaport, J., Seidman, E., Toro, P., McFadden, L. S., Reischl, T. M., Roberts, L. J., Salem, D. A., Stein, C. H., \& Zimmerman, M. A. (1985). Collaborative research with a mutual-help organization. Social Policy, 15, 12-24.

Weber, G. H. (1982). Self-help and belicis. In G. H. Weber \& L. M. Cohen (Eds.), Beliefs and self-help (pp. 13-30). New York: Human Sciences.

Zinman, S., Harp, H. T., \& Budd, S. (1987). Reaching across: Mental heatth clients helping each other. Riverside: California Network of Mental Health Clients. 